\title{
A VELHICE NO OLHAR DOS ACADEMICOS DE ENFERMAGEM, DIREITO E PEDAGOGIA
}

\author{
Simone Oliveira Ferreira ${ }^{1}$ \\ Andréa Evangelista Lavinsky² \\ Talita Machado Levi ${ }^{3}$ \\ Raimunda Silva D'Alencar ${ }^{4}$
}

\section{resumo}

Este estudo propõe analisar os significados da velhice atribuídos por acadêmicos da Universidade Estadual de Santa Cruz, considerando a importância dessa temática, visto que a velhice faz parte do processo de evolução humana e esta tem se tornado um fenômeno global. Trata-se de uma pesquisa qualitativa, realizada no período de 2014 a 2016 por meio de entrevista semiestruturada, que contou com a participação de vinte e dois acadêmicos dos cursos de Enfermagem, Pedagogia e Direito. Os dados analisados revelaram que a maioria

1 Graduada em Enfermagem pela Universidade Estadual de Santa Cruz. Pós-graduanda do Curso de Especialização em Docência do Ensino Superior. Pós-graduanda do Curso de Especialização em Enfermagem do Trabalho e Gestão em Segurança do Trabalho. Pesquisadora do Núcleo de Estudos do Envelhecimento/DFCH-UESC. E-mail: simoneenfer@outlook.com.

2 Graduada em Enfermagem. Mestre em Enfermagem pela Universidade Federal da Bahia. Professora Assistente da Universidade Estadual de Santa Cruz - UESC, vinculada ao Departamento de Ciências da Saúde. Pesquisadora do Núcleo de Estudos do Envelhecimento/DFCH-UESC. E-mail: aelavinsky@uesc.br.

3 Graduada em Enfermagem. Doutora em Medicina em Saúde Humana pela Faculdade de Medicina e Saúde Humana. Professora Adjunta da Universidade Estadual de Santa Cruz - UESC, vinculada ao Departamento de Ciências da Saúde. Pesquisadora do Núcleo de Estudos do Envelhecimento/ DFCH-UESC. E-mail: Talita_uesc@hotmail.com.

4 Graduada em Filosofia. Mestre em Sociologia Rural pela Universidade Federal do Rio Grande do Sul. Professora Assistente da Universidade Estadual de Santa Cruz - UESC, vinculada ao Departamento de Filosofia e Ciências Humanas - DFCH. Pesquisadora do Núcleo de Estudos do Envelhecimento/ DFCH-UESC. E-mail: r_alencar2@yahoo.com.br. 
dos acadêmicos apresenta uma maneira singular de entender a velhice. As expectativas estão voltadas para uma vida longeva, um envelhecimento ativo e pautado no respeito. $\bigcirc$ fato de envelhecer não vem expresso nas falas como algo negativo, mas foram direcionadas preocupações para uma velhice não compartilhada, com ausência do núcleo familiar e a falta de mecanismos na sociedade que garantam de forma efetiva os direitos dos idosos. Apesar das significações e representações positivas no que se refere à velhice, percebeu-se em alguns relatos a falta de proximidade com essa fase. Esta pesquisa mostrou a necessidade de se discutir enquanto sociedade sobre as questões que envolvem os idosos, assim como sobre o preparo do envelhecimento enquanto pessoa que também está envelhecendo, haja vista os reflexos para uma sociedade de idosos, que já é uma realidade.

palavras - chave

Velhice. Representação Social. Estudos Universitários.

\section{Introdução}

Uma das maiores conquistas culturais de um povo em seu processo de humanização é o envelhecimento de sua população. Tal conquista é resultado dos avanços das políticas de saúde pública e sociais, que têm proporcionado melhores condições de vida para a população (BRASIL, 2015).

Segundo dados do Instituto Brasileiro de Geografia e Estatística (IBGE, 2014), a expectativa de vida dos brasileiros aumentou para 75 anos, 2 meses e 12 dias em 2014. A população brasileira economicamente ativa deverá atingir seu máximo em 2030 com uma projeção de 208 milhões de brasileiros (BRASIL, 2015).

Alexandre Kalache, ex-diretor do Departamento de Envelhecimento e Saúde da Organização Mundial da Saúde (OMS) e atual presidente do Centro Internacional de Longevidade (ILC-Br), adverte que a população viverá trinta anos a mais em relação à expectativa de vida das gerações remotas; salienta, ainda, que a longevidade e o envelhecimento devem ser contemplados de maneira positiva (ROSA; JORDÃO; DAMAZIO, 2014). Delineando este panorama acerca da mudança na pirâmide etária, considera-se oportuno trazer à tona a discussão das diferentes representações e significados atribuídos à velhice e ao processo de envelhecimento em virtude de que, por muito tempo, fora 
introjetada a ideia de que a senescência era uma fase de abandono e solidão (GOMES; LOUREIRO; ALVES, 2012).

Scortegagna e Oliveira (2012) fazem menção que, infelizmente, dentro da conjuntura social, ainda permeiam os paradigmas acerca da velhice impostos culturalmente, e reforçam que desconsiderar a velhice revela-se como um preconceito que se perpetua ao longo dos anos. É nesse contexto que a velhice pode tornar-se um problema social. Quando não encarada como uma conquista, os idosos passam a ser vistos como um encargo para a família, para o Estado e para a sociedade (GOMES; LOUREIRO; ALVES, 2012).

A educação surge como uma oportunidade de ação, podendo gerar uma visão diferenciada acerca do idoso e da velhice, a partir do momento em que leva à sociedade o esclarecimento de como aprender a respeitar, lidar e viver o próprio envelhecimento, possibilitando caminhos para que o idoso vivencie a velhice em um mundo mais justo, em que seus direitos sejam contemplados e respeitados (SCORTEGAGNA; OLIVEIRA, 2012). Nesse sentido, Sicco (2011) propõe que criar momentos de reflexão durante a formação acadêmica possibilita aos jovens rever conceitos e romper tabus, onde as abordagens sobre $\mathrm{o}$ envelhecimento podem abrir espaço para o diálogo, permitindo ouvir o que eles têm a dizer sobre a temática. Considerando que a transição demográfica modificará a estrutura epidemiológica vigente nos próximos anos, formar profissionais conscientes, despidos de preconceitos e concepções ultrapassadas, torna-se um passo fundamental na busca por uma sociedade que respeite o idoso dentro de sua singularidade (MEDEIROS; RODRIGUES; NÓBREGA, 2012).

Compreender como jovens acadêmicos percebem o envelhecimento, a velhice e o próprio idoso torna esta pesquisa relevante pela possibilidade de construção de representações positivas sobre essa fase do ciclo da vida, podendo construir estratégias para a reinserção social do idoso, e para uma maior reflexão sobre o envelhecimento junto a acadêmicos, em uma perspectiva multidisciplinar. $\mathrm{O}$ interesse em registrar este estudo surgiu mediante a participação no Programa de Iniciação Científica da Fundação de Amparo ao Pesquisador do Estado da Bahia (FAPESB) e da Universidade Estadual de Santa Cruz, quando o foco de pesquisa voltou-se para os significados da velhice atribuídos por acadêmicos da referida instituição. Portanto, com o intuito de contribuir para o debate e para a ampliação do corpo de conhecimento em torno dessa temática, o presente artigo tem como objetivo analisar os significados da velhice atribuídos por acadêmicos dos cursos de Enfermagem, Direito e Pedagogia da Universidade Estadual de Santa Cruz. 
Trata-se de um estudo qualitativo, de caráter descritivo, desenvolvido no período de 2014 a 2016, na Universidade Estadual de Santa Cruz, localizada no município de Ilhéus-BA. Este é um subprojeto que integra a pesquisa "O significado da velhice na perspectiva de acadêmicos da Universidade Estadual de Santa Cruz", do Núcleo de Estudos sobre o Envelhecimento desta Universidade. O trabalho foi aprovado pelo Comitê de Ética em Pesquisa (parecer número 83.379, de 19/09/2012).

Participaram da pesquisa vinte e dois acadêmicos, por meio de convite oficial junto ao colegiado dos cursos de Enfermagem, Direito e Pedagogia matriculados nos turnos diurno e noturno, do primeiro e oitavo semestres, com intuito de identificar a percepção que esses estudantes têm acerca da temática ao adentrarem na graduação e a possível influência, ao longo da jornada acadêmica, da grade curricular de seus cursos na construção das representações sociais acerca da velhice e do envelhecimento. A escolha dos cursos deveu-se ao fato de entender-se que os acadêmicos de Enfermagem prestarão cuidados aos idosos, os de Pedagogia assumirão o compromisso de transferir valores às gerações mais novas através do ensino e os acadêmicos do curso de Direito tratarão dos direitos de cidadania, defendendo as prerrogativas dos idosos.

Para seleção da amostra, os seguintes critérios de elegibilidade foram estabelecidos: estar matriculado no primeiro ou último período dos respectivos cursos de graduação, e aceitar participar voluntariamente do estudo. Utilizou-se a entrevista semiestruturada como técnica de coleta de dados. O instrumento, constituído por questões fechadas e abertas, continha informações referentes à idade, estado civil, relações familiares, escolaridade, ocupação, religião e dados socioeconômicos de cada entrevistado; das questões abertas, vinte e quatro perguntas retratavam a convivência dos acadêmicos com idosos e tratavam da violência (maus-tratos) contra idosos, do conhecimento acerca do Estatuto do Idoso, do processo de ensino/aprendizado na senescência e de como o curso abordava a velhice e o processo de envelhecimento.

Convém salientar que três questões norteadoras foram estabelecidas para este estudo: a) "O que você entende por velhice?"; b) "Qual a sua expectativa quanto ao seu próprio envelhecimento?"; e c) "Você considera adequado o tratamento dispensado pela sociedade ao idoso?". Vinte e duas entrevistas, transcritas na íntegra, compuseram o corpus deste estudo, conforme exposto na tabela a seguir: 
Tabela 1 - Números de entrevistas realizadas por curso e semestre.

\begin{tabular}{llll}
\hline & Primeiro semestre & Último semestre & Total de entrevistas \\
\hline Enfermagem & 2 & 5 & 7 \\
Direito & 3 & 4 & 7 \\
Pedagogia & 3 & 5 & 8 \\
\hline
\end{tabular}

Fonte: Elaborada pelos autores.

O levantamento dos dados ocorreu entre os meses de novembro de 2014 e janeiro de 2015. Os dados foram analisados na perspectiva da Análise de Conteúdo proposta por Bardin (2011), que preconiza os seguintes passos: pré-análise, codificação e categorização.

Os princípios éticos norteadores desta pesquisa estão contemplados na Resolução 510/2016 do Conselho Nacional de Saúde, regulados pelas Diretrizes e Normas de Pesquisas em Seres Humanos. Todos os participantes consentiram à participação por manuscrito mediante a assinatura do Termo de Consentimento Livre e Esclarecido - TCLE. Para assegurar-lhes o anonimato na identificação de seus relatos, foi utilizada a letra "E", que representa a inicial da palavra entrevista, seguida do número da entrevista analisada e da identificação do curso, bem como do período acadêmico em que os estudantes estão. Por exemplo: “E12, Enfermagem, 8osemestre".

\section{Resultados e discussão}

Este item ilustra os dados relativos ao perfil dos participantes e os resultados das análises das informações.

\subsection{Perfil dos participantes do estudo}

O estudo demonstrou uma realidade amostral de vinte e dois participantes, com idade entre 18 e 59 anos, sendo treze mulheres e nove homens. No que se refere ao convívio cotidiano com a pessoa idosa, treze acadêmicos informaram conviver com idosos na família e na comunidade; três estudantes relataram que, além da convivência com idosos nos diversos cenários da sociedade, residem com familiar idoso; e seis afirmaram não ter contato direto com idosos, contudo se deparam com idosos no transporte coletivo, nas filas de banco, na universidade e nos demais espaços sociais. 
No que tange aos significados da velhice atribuídos pelos acadêmicos de Enfermagem, Direito e Pedagogia, após análise de conteúdo e tratamento das entrevistas, foram identificadas as seguintes categorias, que emergiram a partir das três questões citadas no início deste estudo: 1) "Experiências e maturidade na visão de acadêmicos: (re)significando a velhice"; 2) "Perspectivas dos acadêmicos sobre a longevidade: viver muito, viver bem e com dignidade"; e 3) "Visão da velhice respeitada". Assim, as entrevistas foram agrupadas nessas três categorias, de acordo com a semelhança de conteúdo.

\subsubsection{Experiências e maturidade na visão de acadêmicos: (re)significando a velhice}

Conceituando a velhice, Ferreira et al. (2012) referem-na como sendo um processo individual, natural e inevitável para qualquer ser humano no desenvolvimento da vida, e a maneira como cada pessoa evidencia essa fase fará com que essa etapa seja vivenciada de distintas formas. Os referidos autores destacam, ainda, que as mudanças biológicas fazem parte do processo de envelhecimento e que este não é caracterizado somente pelo surgimento de rugas, progressiva perda da elasticidade e do viço da pele e pela diminuição da força muscular. O envelhecimento contempla, também, mudanças psicossociais como a consciência da aproximação do fim da vida, declínio do prestígio social e alterações funcionais que criam a necessidade cotidiana de ajuda para desempenhar as atividades básicas, além das perceptíveis transformações socioeconômicas e políticas (FERREIRA et al., 2012). Ressalta-se que, apesar das alterações fisiológicas e funcionais que podem trazer modificações próprias desse processo, estas não tornam a velhice uma fase apenas de perdas, mas também de experiências, como destacado na fala dos entrevistados dos cursos de Enfermagem, Pedagogia e Direito:

A velhice é uma fase de mudança que acontece com todos, são fisiológicas, e que podem trazer problemas para a pessoa, mas que também são grandes experiências. Porque só quem vive muito tempo tem as experiências (E6, Enfermagem, $8^{\circ}$ semestre). 
Velhice é você criar certa maturidade, estar avançado na idade, mas não quer dizer que é velho, inútil, entendeu?... Velhice, eu entendo por avanço da idade (E7, Pedagogia, $1^{\circ}$ semestre).

Velhice é uma consequência de viver, todo mundo envelhece (E28, Direito, $1^{\circ}$ semestre).

Os relatos atribuíram à velhice a significação de uma fase marcada por mudanças que podem ser fisiológicas, patológicas e/ou sociais, considerando que essas mudanças acontecem durante o percorrer do curso vital e que esse processo sofre influências das vivências abarcadas por cada indivíduo, fato que colabora para construção positiva das experiências pessoais. Um acadêmico do curso de Enfermagem do oitavo semestre abordou também a questão da maturidade que, de acordo com o mesmo, é adquirida com o avanço da idade, considerando que o fator da idade cronológica não é uma problemática. Como enfoque, o acadêmico de Pedagogia do primeiro semestre destacou que o fato de ser idoso não significa ser inútil, mas outras significações positivas podem ser construídas também nessa etapa da vida a partir das vivências/experiências, que são privilégios apenas daqueles que vivem muito. O relato de um acadêmico do curso de Direito do oitavo semestre ilustra a visão do reconhecimento da velhice e do preparo que já está sendo almejado para garantir uma velhice com funcionalidade, dentro do que considera um envelhecer com qualidade:

Até uns tempos atrás, o idoso não era preparado para envelhecer. Minhas avós, que faleceram, não foram preparadas para envelhecer, morreram com oitenta e poucos anos, mas elas simplesmente não esperavam chegar a essa idade; e elas faleceram extremamente enfermas, com muitos problemas, todas as duas, exatamente porque elas não se prepararam. Então, acabaram desenvolvendo Alzheimer, coisas debilitantes, elas acabaram enfermas, na cama. Uma amputou parte da perna [...] complexo. Os meus pais, entretanto, já estão se preparando para envelhecer. O meu pai tem 58 anos, a minha mãe 54, e eles se preparam, já mentalizam ingressarem nessa idade, passarem dos 60 com saúde, bem, dinâmicos. Então pra gente, a perspectiva é essa (E12, Direito, $8^{\circ}$ semestre).

Observa-se que o estudante supracitado trouxe, em seu relato, a convivência com as avós doentes, expressando que a falta de preparo levou as idosas ao declínio funcional. Contudo, tanto o entrevistado como seus familiares já reconhecem a positividade da velhice com preservação da autonomia e independência e, diante disso, delineiam os próprios caminhos para vivenciar um envelhecimento dinâmico, almejando longeviver bem.

Nesse sentido, Côrte e Brandão (2013) afirmam que envelhecer de forma ativa implica atitude pessoal de otimismo perante a vida e requer medidas 
capacitadoras dos mais velhos e da família. Contudo, salientam também que viver muito e bem depende de inúmeros fatores: sociais, ambientais, espirituais e genéticos.

Vale destacar que a imagem corporal representa as mudanças que ocorrem ao longo do tempo, anunciando o envelhecimento. Nesse sentido, para que o idoso ressignifique o autoconceito em relação às capacidades, competências, aparência física e aceitabilidade social, é fundamental superar o processo de envelhecer como algo proibido, vergonhoso e incompetente e, para isso, torna-se necessário desmistificar o olhar negativo sobre a velhice em prol de uma imagem corporal que ultrapasse os declínios físicos e estéticos e que beneficie pensar em novas formas de relações e percepções de corpo na sociedade (FRANÇA et al., 2016).

O entrevistado do curso de Enfermagem do oitavo semestre mencionou que a velhice pode ir além do físico, sendo um fator mais psicológico, transcendendo as características ou alterações físicas, indo além das mudanças estéticas e da idade cronológica:

Eu acho que a velhice vai além do físico! É mais mental do que fisicamente. Pela questão das pessoas acharem que porque tá seguindo a idade tem que tá diferente, tem que ser tratado de forma diferente, de forma especial por causa da idade. Mas não é um problema (E1, Enfermagem, $8^{\circ}$ semestre).

De acordo com Corrêa (2013), a questão da saúde mental e social para a promoção de um envelhecimento ativo muitas vezes é negligenciada. A preservação da saúde mental reflete uma característica de maior capacidade funcional de todas as idades, podendo ser evidenciada através da autoestima e das expectativas positivas diante da vida. Portanto, a saúde física e a saúde mental influenciam-se mutuamente. Quando se considera a saúde mental, as vivências e as experiências construídas ao longo da vida permitem compreender outras dimensões para se compartilhar uma velhice mais positiva e feliz.

Os relatos anteriores revelam expressões voltadas para a experiência, maturidade e vigor mental, utilizadas pelos entrevistados como um contraponto à velhice como forma de viver e passar pelo processo de envelhecer, rompendo com os estereótipos. Assim, os acadêmicos de Enfermagem, Direito e Pedagogia encontram, através dessas expressões, o desejo de adentrar nesse ciclo, atribuindo outras significações otimistas acerca da velhice. 

de forma acelerada na sociedade atual, sinalizando o envelhecimento populacional e a perspectiva de crescente longevidade. Os discursos abaixo, dos alunos de Pedagogia e Enfermagem do primeiro e último semestre, respectivamente, demonstram o desejo de envelhecer, de viver muitos anos de vida e sem incapacidades físicas, destacando a saúde e a longevidade como algo a ser alcançado na velhice:

Espero chegar até os cem anos, porque envelhecer é sinal de viver. Quem não quer viver tem que morrer logo pra não chegar até a idade. Então eu espero envelhecer sim (E5, Pedagogia, $1^{\circ}$ semestre).

Eu espero envelhecer muito, viver, viver bem, um envelhecimento sadio. Se eu não envelhecer vou morrer cedo, o que é ruim (E22A, Enfermagem, $8^{\circ}$ semestre).

Sant'Ana-Loos et al. (2016) relatam que a superação dos paradigmas relacionados à velhice e os avanços nas áreas de estudos gerontológicos na Psicologia, Sociologia e outras ciências colaboraram para elevar a qualidade de vida, a longevidade, assim como o número de idosos ativos. Essas conquistas geram nas pessoas o desejo do bem viver e do envelhecer, que esperam chegar à senescência e viver bem durante muitos anos de vida, conforme os relatos acima.

Um entrevistado do curso de Pedagogia, do primeiro semestre, salienta, em seu relato, o desejo de vivenciar a longevidade, com a preservação dos laços e vínculos familiares, sendo que a família aparece como eixo principal dentro do que considera uma velhice tranquila:

Mas eu quero ter um envelhecimento sadio, com minha família, e que possa ter uma morte tranquila. O problema da sociedade é pensar no ser humano, pensar que não morre, por isso que existe tanto preconceito em relação ao idoso, porque o jovem pensa que é imortal, e só o tempo vai dizer o contrário (E9, Pedagogia, $1^{\circ}$ semestre).

Nesse contexto, um estudo da Universidade Católica Portuguesa (2012) aborda que uma das estratégias para promover o envelhecimento bem-sucedido passa, dentre outros, pelo desenvolvimento de atividades relacionadas com o fomento da proximidade com a família, de modo a preservar os laços afetivos e as competências gerais do idoso. 
O medo de chegar à velhice com algum tipo de dependência física constitui uma barreira que acaba distanciando a velhice das demais fases da vida, sendo essa esquecida justamente pelas perdas que podem ocorrer nesse processo, conforme expresso na fala de uma acadêmica do curso de Pedagogia:

Eu espero que eu fique muito velha [...]. Espero que eu tenha filhos, netos e fique rodeada de netos, de filhos [...] idosa. Mas eu fico pensando: será que eu vou ser uma idosa acamada, uma idosa dependente, uma idosa cega? Eu não quero assim [...]. Quem quer, né? [...] Mas eu quero sim envelhecer, chegar lá pra os meus cem anos com saúde e bem-estar (E20, Pedagogia, $8^{\circ}$ semestre).

Em virtude de superar os anseios apresentados pela participante acima, deve-se investir na promoção de programas sociais e ações com foco na manutenção da capacidade funcional dos idosos, integrando ações multiprofissionais para a detecção precoce de problemas de saúde, sendo metas fundamentais não só do governo, mas também dos demais setores da sociedade, permitindo, dessa forma, o planejamento de estratégias de promoção e prevenção da saúde (FALLER; TESTON; MARCON, 2015). Ressalta-se que, embora a maioria dos entrevistados de Enfermagem e Pedagogia tenha expressado o desejo de vivenciar a senescência, dois alunos de Enfermagem tiveram dificuldade para refletir acerca do envelhecimento, enxergando essa fase da vida como uma etapa bem distante:
Ah, eu não sei. Tanto que teve uma atividade em Saúde do Idoso que era para a gente escrever uma carta como se tivesse cinquenta anos mais velho. Aí eu fiquei, assim, viajando, porque eu não sei (E21, Enfermagem, $1^{\circ}$ semestre).
Então, eu nunca pensei nisso não, nunca pensei em ficar mais velho não, no envelhecimento propriamente dito. Nunca pensei não. Não tenho muitas expectativas não (E25, Enfermagem, $1^{\circ}$ semestre).

Podemos observar que os acadêmicos do curso de Enfermagem do primeiro semestre, quando questionados sobre a temática, demonstram enxergar a velhice como uma fase distante. É possível que esses estudantes estejam adentrando no espaço acadêmico e ainda não tenham tido a oportunidade de discutir sobre tais questões. Talvez a falta de diálogo acerca da velhice enquanto criança e adolescente faça com que adultos tenham essa dificuldade de se enxergar como alguém que está envelhecendo. Caldas e Thomaz (2010) apontam que o distanciamento do envelhecimento revela uma falta de proximidade com a velhice, com o idoso e um afastamento do que é passado no envelhecimento humano, o que pode colaborar para o não enfrentamento da velhice. 
Diante da questão do envelhecimento ativo, os sujeitos expressaram, por meio das entrevistas, justamente essa proposta do envelhecer de forma dinâmica, contemplando o bem-estar, a saúde e a independência para realizar suas tarefas da vida diária, abarcando também mudanças de paradigmas, pois permeia o desejo de continuar exercendo atividades prazerosas, de interagir com a sociedade, de se enriquecer culturalmente, não atribuindo o fator da idade a um empecilho, conforme explicitado nas falas dos estudantes de Pedagogia:

Eu espero envelhecer bem, com saúde, e que não precise depender de outras pessoas pra me locomover e poder fazer qualquer coisa... Ir ao banco, eu penso que quero envelhecer bem, ser atualizada, entendeu?! Com saúde (E2, Pedagogia, $8^{\circ}$ semestre).

Eu quero envelhecer com espírito jovem. Não quero estacionar no tempo, eu pretendo ser uma idosa que saia, que converse bastante com meu neto, que não pare assim na vida por conta da idade (E3, Pedagogia, $8^{\circ}$ semestre).

O envelhecimento saudável foi adotado pela Organização Mundial da Saúde (OMS), consistindo no processo de otimização de oportunidades para saúde, participação e segurança, na perspectiva de melhorar a qualidade de vida das pessoas que envelhecem, oportunizando uma experiência positiva frente à velhice (OMS, 2015).

Os estudantes de Pedagogia contemplaram, em suas falas acima, a importância do envelhecer com a capacidade funcional preservada, com independência para resolutividade de problemas e questões que envolvam o exercício da cidadania, da manutenção do desenvolvimento intelectual, bem como o não estacionamento no tempo e a preservação dos vínculos intergeracionais. Todo esse arcabouço de fatores destacados revela o desejo de se chegar à velhice de forma ativa e saudável. A dependência gera nos entrevistados uma insegurança de adentrar na velhice, pois a independência faz parte do processo evolutivo do ser humano e, quando esta se perde, a vida se torna limitada.

Freitas, Queiroz e Sousa (2010) consideram que, conforme a pessoa envelhece, sua qualidade de vida é diretamente determinada por sua capacidade em manter a autonomia e a independência, pontuando que a maioria dos idosos tem receio de chegar à velhice com algum tipo de dependência ou de não poder executar atividades corriqueiras da vida diária. O receio de encontrar, na velhice, a dependência no processo de tomada de decisão chama atenção para o fortalecimento de abordagens de promoção de vida saudável, no intuito de afastar as morbidades e prevenir as incapacidades, preservando a autonomia e independência. Envelhecer com capacidade para desenvolver novas 
habilidades e potencialidades traz a oportunidade de recomeçar, conforme referido no relato do estudante de Pedagogia a seguir:

Espero estar muito bem, pelo menos com saúde, porque saúde é a base para um bom envelhecimento; quero continuar fazendo as coisas que gosto e descobrindo novos projetos, desejo viver de forma ativa (E15, Pedagogia, $8^{\circ}$ semestre).

O entrevistado do curso de Pedagogia citado acima sinaliza a vontade de envelhecer de forma ativa. Essa visão denota o vislumbramento de uma "nova velhice", na qual as pessoas estão desejando viver, envelhecer de forma mais participativa na sociedade, assumindo papéis diferenciados na família, bem como penetrar em novos espaços que antes eram delimitados. Algo semelhante é almejado pela acadêmica de Enfermagem do oitavo semestre:

Mas eu quero ter uma família, quero ter uma família grande, quero... ser feliz. Quero viver minha vida, não ficar parada. Quero fazer atividade física, quero ter lazer (E19, Enfermagem, $8^{\circ}$ semestre).

Segundo Goldenberg (2011), homens e mulheres podem envelhecer dando prosseguimento aos seus projetos existenciais, ou seja, permanecer cantando, dançando, buscando a felicidade e o prazer, transgredindo as normas e tabus existentes. Pereira (2012) compartilha dessa visão, mencionando que a nova geração de idosos está nas ruas, participando de atividades culturais, educativas, políticas, comunitárias; é consumidora exigente de bens de serviço, demonstrando não ter a mesma conduta da geração anterior.

Por tudo que foi explanado até o momento, o desejo de ser feliz também na velhice foi evidenciado de forma explícita na fala do estudante de Enfermagem. Essa felicidade vem englobada pela forte presença do núcleo familiar, preservação daquilo que se gosta ou sempre gostou de fazer e o não esquecimento dentro do cenário social.

Compreende-se, por meio das falas aqui discutidas, que a repercussão da longevidade vai depender da história de vida pessoal. Chegar à velhice significa que um novo horizonte pode ser descoberto, mas para chegar a essa fase é preciso desenvolver novas formas de se garantir o bem-estar e a alegria de viver em todas as etapas da vida. Essa é a proposta do envelhecimento participativo, também salientado pelos estudantes que já delineiam os próprios caminhos para uma senescência com qualidade de vida. 

sociedade em virtude de representarem a cultura vivificada das gerações mais remotas, além de abordar experiências que os fizeram evoluir em seu processo histórico de vida (MOTTA, 2010). Nesse contexto, esta categoria aborda a temática "velhice respeitada", onde os relatos dos acadêmicos permitem identificar o desejo de chegar à velhice em uma sociedade preparada para acolher, respeitar e garantir os direitos da pessoa idosa:

E que eu venha a ser respeitada e reconhecida, assim como eu faço com os idosos (E17, Direito, $1^{\circ}$ semestre).

Para Morais (2015), no que se refere ao respeito para com os idosos, esse valor vem sendo negligenciado, desencadeando situações de desrespeito para com os mais velhos. Isso é o resultado de uma sociedade marcada pelo capitalismo, em que a juventude é valorizada pela produtividade em detrimento da valorização da maturidade.

A educação surge como uma oportunidade para promoção da orientação sobre valores. Nesse sentido, carecemos da disseminação de conhecimento que proponha a transformação na sociedade e acarrete bons valores nas crianças, jovens e adultos, ensinando a justiça, ética, moral, solidariedade e o respeito mútuo, e não somente conhecimentos relacionados ao campo intelectual, pois, acima de tudo, como seres humanos, precisamos viver em coletividade (MORAIS, 2015).

Faz-se necessário discutir, enquanto sociedade, as questões que envolvem os idosos, entendendo que é fundamental garantir direitos e construir uma sociedade mais justa para que os jovens de hoje contemplem, no futuro, uma velhice pautada no respeito e na dignidade humana. Ou seja, não se trata apenas de uma discussão marcada no hoje, mas também no amanhã, como bem salientado na fala do acadêmico de Pedagogia a seguir:

Eu espero envelhecer tendo uma sociedade melhor pra conviver; eu procuro sempre estar conversando com as pessoas... Falando em sala de aula de problemas atuais; problemas passados e problemas que podem surgir no futuro também em decorrência desses que nós resolvemos hoje. Então é interessante que a gente tenha essa visão... De que amanhã esse idoso que a gente trata hoje pode ser simplesmente um de nós (E18, Pedagogia, $8^{\circ}$ semestre). 
O movimento crescente de idosos na sociedade estabelece o desafio de introduzir a temática do envelhecimento populacional, enfatizando o respeito ao idoso e o reconhecimento do mesmo enquanto pessoa (MIRANDA; MENDES; SILVA, 2016). Na perspectiva de garantir, na velhice, uma base de proteção ao cidadão idoso, a fala a seguir de uma estudante do curso de Direito reforça a importância da presença da família e a participação da sociedade neste processo:

Eu espero que quando chegar minha fase de envelhecimento eu seja respeitada, amada por minha família, e assim espero também que a sociedade, ao decorrer dos anos, venha se conscientizar como deve tratar os idosos (E10, Direito, $8^{\circ}$ semestre).

É necessário situar o processo de envelhecimento dentro do contexto social, entendendo a necessidade de discutir sobre como atender às necessidades da pessoa idosa, seja em relação aos aspectos econômicos, políticos ou socioculturais (MIRANDA; MENDES; SILVA, 2016). Ressalta-se que, para concretizar esses aspectos, é preciso modificar alguns mecanismos, conforme expresso pelo acadêmico do curso de Direito abaixo:

Eu acho que a sociedade do século XX, essa sociedade é de idosos... Então, por isso, deve-se mudar alguns mecanismos pra lidar com essa geração (E16, Direito, $1^{\circ}$ semestre).

Nesse sentido, para garantir a concretude dos direitos inerentes à pessoa idosa, a rede de proteção deve ser tecida na prática por instrumentos legais (leis, decretos, resoluções, portarias), órgãos, instituições, ações (políticas, programas, projetos e serviços) e pessoas físicas que garantam a efetividade de tais marcos normativos em ações concretas que beneficiem esses atores sociais (RAMOS, 2011). Em relação aos pilares que sustentam e possibilitam uma velhice estruturada, a saber, trabalho, saúde e o direito previdenciário, algumas falas dos estudantes de Direito contemplaram determinantes, conforme apresentado a seguir:

Do meu envelhecimento eu espero conseguir ter uma base e uma aposentadoria, um bom estado de saúde. Eu espero ter melhorias na sociedade, tipo na área da saúde, uma atenção maior, uma assistência maior, porque quando se é velho precisa-se de muito mais atenção do que quando a gente é mais jovem. Então a gente está mais apto a ficar doente, a ter mais infecção, e isso pode acabar até causando uma mortalidade maior pra essa faixa de idade (E11, Direito, $8^{\circ}$ semestre). 
Eu espero que no meu envelhecimento eu ainda esteja bem. Que eu tenha uma boa condição; hoje, como jovem, desejo me estruturar para que na minha velhice eu possa gozar daquilo que eu conquistei. Que eu seja uma pessoa ativa, mesmo na velhice, mesmo com limitações, que eu continue, de alguma forma, sendo produtivo no âmbito da sociedade (E8A, Direito, $8^{\circ}$ semestre).

Rolim et al. (2014) abordam os direitos das pessoas da terceira idade, dentre estes, o direito à vida, em que a família e o Estado têm o dever de amparar o idoso; direito ao respeito, no qual o idoso não pode sofrer discriminação de qualquer natureza; a garantia ao atendimento das necessidades básicas, como a aposentadoria e o acesso à saúde e à educação. Todos estes se configuram como direitos existenciais e significantes, contrapontos na garantia da dignidade da pessoa idosa.

A garantia à saúde e a um sistema de saúde efetivo também é apontado por um estudante do oitavo semestre do curso de Direito. Contudo, um aspecto marcante foi observado na fala de um entrevistado do curso de Enfermagem do oitavo semestre, sendo esse o receio de ser abandonado em abrigos:

Eu espero depender menos da questão de médicos e hospitais; preparar o
corpo para chegar nessa fase com saúde. Essa é minha expectativa; também
ter uma vida financeira já estável para poder depender menos das pessoas,
porque essa também é uma questão muito importante a se voltar. Não quero
ser jogado em algum asilo, e ficar de forma descuidada. Minha preocupação é
essa, da saúde e da questão financeira também (E8B, Enfermagem, $8^{\circ}$ semestre).

Segundo Morais (2015), salvo casos como não ter família, notamos que o cuidado e o respeito à dignidade dos idosos ainda é um desafio a ser vencido. Tal fato revela que a preocupação dos entrevistados acima tem fundamento. De acordo com o Estatuto do Idoso (BRASIL, 2003), a família deve acolher a pessoa idosa, proporcionando condições necessárias para sobrevivência da mesma. No que se refere ao direito básico à saúde, torna-se necessária a estruturação de serviços de saúde acessíveis, focando na promoção da saúde, na prevenção, no tratamento e no manejo de enfermidades não somente na velhice, mas ao longo do percurso vital, preservando a qualidade de vida em todos os seus ciclos até a morte (ACIOLE; BATISTA, 2013).

Destaca-se que a contemplação desses resultados é atingida em sua materialidade quando se emprega a mesma prioridade a outros fatores determinantes e condicionantes para garantir a qualidade de vida, a saber, a alimentação, a moradia, o saneamento básico, o meio ambiente, o trabalho, a renda, a educação, o transporte, o lazer e o acesso aos bens e serviços essenciais (BRASIL, 2015). Nessa terceira categoria, os acadêmicos de Pedagogia debateram questões 
voltadas para o contexto social em que vivem os idosos no cenário atual, revelaram o desejo de envelhecer em uma sociedade mais preparada em termos de educação, trabalho e garantia dos direitos da pessoa idosa, enquanto os estudantes de Enfermagem pontuaram a importância de um sistema de saúde que seja resolutivo e que contemple as reais necessidades dos idosos. Já os entrevistados do curso de Direito assumiram a importância de se preservar os direitos que são assessorados pelo Estatuto do Idoso, considerando o papel e a representação social do idoso como algo a ser valorizado nessa etapa da vida.

Assim, analisando as concepções dos acadêmicos de Pedagogia, Enfermagem e Direito acerca da temática "velhice respeitada", percebemos que esses sujeitos esperam evoluir para uma sociedade em que haja respeito ao idoso. Para isso, os jovens consideram a necessidade de diálogo e reflexão conjunta com a sociedade, onde cada um reveja conceitos e entenda a importância de envelhecer com respeito e dignidade.

\section{Considerações finais}

A velhice representa várias significações para os participantes deste estudo, sendo que o fato de envelhecer não vem expresso como algo negativo, pois cada um espera ter boas histórias para contar nessa etapa da vida. A maioria dos entrevistados evidenciou a vontade de vivenciar uma velhice com autonomia, independência, garantia de direitos e respeito à pessoa idosa; em algumas falas, percebe-se o distanciamento entre a juventude e a velhice.

Entretanto, durante o processo de construção deste estudo, algumas limitações foram identificadas e, dentre essas, o fato de alguns estudantes apresentarem receio em participar da pesquisa. Muitos expressaram o desejo de não participar, em especial os acadêmicos matriculados no primeiro semestre dos cursos aqui estudados, pois identificavam certa dificuldade em pensar sobre a temática, reconhecendo o envelhecimento como algo distante; outros explanaram que ser jovem os põe numa zona de conforto, como se a velhice nunca fosse chegar a eles.

Nesse aspecto, a propagação de abordagens sobre essa temática para todas as gerações possibilitará o rompimento das barreiras que distanciam a velhice das demais etapas da vida. Conhecer o modo como os acadêmicos percebem e idealizam a velhice agregou grande aprendizado a respeito dos diferentes significados e representações que cada sujeito constrói ao longo de sua vida. Assim, ao incluir as questões do processo de envelhecimento no ambiente acadêmico, cria-se um espaço de reflexão que permite configurar mudanças assertivas no modo de pensar sobre a velhice, passando a reconhecê-la como um êxito da sociedade atual. 
THE OLD AGE THROUGH THE VIEW

OF ACADEMICS OF NURSING, LAW

AND PEDAGOGY

abstract

This study proposes an analysis of the meanings of old age attributed by academics of the State University of Santa Cruz, considering the importance of this subject, since old age is part of the process of human evolution, which has become a global phenomenon. This is a qualitative research, carried out from 2014 through 2016 by means of a semi-structured interview, which was attended by twenty-two academics from the Nursing, Pedagogy and Law courses. The data analyzed revealed that most academics present a unique way of understanding old age. Expectations are focused on a long life and on an active and respectful aging. The fact of aging is not expressed in the speeches as something negative, but concerns were directed towards an unshared old age, with absence of the family nucleus, and the lack of mechanisms in society that effectively guarantee the rights of the elderly. Despite the positive meanings and representations regarding old age, it has come to attention in some reports the lack of proximity to this phase. This research showed the need to discuss the issues that involve the elderly as a society, as well as discuss the preparation of aging as a person who is also aging, taking into account the reflexes on an elderly society that is already a reality.

keywords

Old Age. Social Representation. University Studies.

referências

ACIOLE, Giovanni Gurgel; BATISTA, Lúcia Helena. Promoção da saúde e prevenção de incapacidades funcionais dos idosos na estratégia de saúde da família: a contribuição da fisioterapia. Revista Saúde em Debate, Rio de Janeiro, v. 37, n. 96, p. 10-19, jan./mar. 2013. Disponível em: <http://www.scielo.br/scielo.php?pid=S010311042013000100003\&script=sci_abstract\&tlng=pt>. Acesso em: 27 abr. 2018.

BARDIN, Laurence. Análise de conteúdo. 5. ed. Tradução Luís Antero Reto e Augusto Pinheiro. Lisboa: Edições 70, 2011.

BRANDÃO, Vera. Viver bem para longe viver melhor. Revista Portal de Divulgação, São Paulo, v. 34, jul. 2013. Disponivel em: <http://www.portaldoenvelhecimento. com/revista-nova/index.php/revistaportal/article/view/2/2>. Acesso em: 18 jun. 2018. 
BRASIL. Centro Internacional de Longevidade. Envelhecimento ativo: um marco político em resposta à revolução da longevidade. Rio de Janeiro, jul. 2015. Disponível em: $<$ http://ilcbrazil.org/portugues/noticias/active-ageing-a-policy-framework-in-responseto-the-longevity-revolution/>. Acesso em: 7 dez. 2016.

- Ministério da Saúde. Estatuto do Idoso. 2. reimpr. Brasília: Ministério da Saúde, 2003. (Série E. Legislação de Saúde).

CALDAS, Célia Pereira; THOMAZ, Andrea Fernandes. A velhice no olhar do outro: uma perspectiva do jovem sobre o que é ser velho. Revista Kairós Gerontologia, São Paulo, v. 13, n. 2, p. 75-89, nov. 2010. Disponível em: <https://revistas.pucsp.br/index.php/ kairos/article/view/5367/3847>. Acesso em: 7 dez. 2016.

CORREAA, Letícia Rocha. O grupo operativo e a promoção de saúde mental para idosos. Revista Saúde e Desenvolvimento, São Paulo, v. 3, n. 2, p. 96-117, jan./jun. 2013. Disponível em: <http://www.uninter.com/revistasaude/index.php/saudeDesenvolvimento/article/view/162>. Acesso em: 15 dez. 2016.

CÔRTE, Beltrina; BRANDÃO, Vera. Coragem para longeviver. Revista Portal de Divulgação, São Paulo, ano III, n. 34, p. 1-4, jul. 2013. Disponível em: <http://www.portal doenvelhecimento.com/revista-nova/index.php/revistaportal/article/view/1/1>. Acesso em: 15 dez. 2016

FALLER, Jossiana Wilke; TESTON, Elen Ferraz; MARCON, Sonia Silva. A velhice na percepção de idosos de diferentes nacionalidades. Texto \& Contexto Enfermagem, Florianópolis, v. 24, n. 1, p. 128-137, jan./mar. 2015. Disponível em: <http://www.scielo. br/pdf/tce/v24n1/pt_0104-0707-tce-24-01-00128.pdf>. Acesso em: 24 mar. 2018.

FERREIRA, Olívia Galvão Lucena et al. Envelhecimento ativo e sua relação com a independência funcional. Texto \& Contexto Enfermagem, Florianópolis, v. 21, n. 3, p. 513-518, jul./set. 2012. Disponível em: <http://www.scielo.br/pdf/tce/v21n3/v21n3a04. pdf>. Acesso em: 18 jun. 2018.

FRANÇA, Cristiane Braz de Souza et al. Exercício físico e envelhecimento: a percepção de idosas quanto à imagem corporal. Journal Health NPEPS, Tangará da Serra, v. 1 , n. 1, p. 94-108, 2016. Disponível em: <https://periodicos.unemat.br/index.php/jhnpeps/ article/view/1559>. Acesso em: 24 mar. 2018

FREITAS, Maria Célia de; QUEIROZ, Terezinha Almeida Queiroz; SOUSA, Jacy Aurélia Vieira de. O significado da velhice e da experiência de envelhecer para os idosos. Revista da Escola de Enfermagem da USP, São Paulo, v. 44, n. 2, p. 407-412, 2010. Disponível em: <http://www.scielo.br/pdf/reeusp/v44n2/24.pdf>. Acesso em: 15 dez. 2016.

GOLDENBERG, Mirian. Corpo, envelhecimento e felicidade na cultura brasileira. Revista contemporânea, Rio de Janeiro, ano 9, n. 2, 2011. Disponível em: <http:// www.e-publicacoes.uerj.br/index.php/contemporanea/article/view/2143>. Acesso em: 15 dez. 2016

GOMES, Lucy; LOUREIRO, Altair Macedo Lahud; ALVES, Vicente Paulo. O velho e a morte. Revista Kairós Gerontologia, São Paulo, v. 15, n. 4, p. 117-132, ago. 2012. Disponível em: <http://revistas.pucsp.br/index.php/kairos/article/view/17040/12646>. Acesso em: 15 dez. 2016.

INSTITUTO BRASILEIRO DE GEOGRAFIA E ESTATÍSTICA (IBGE). Censo Demográfico 2014. Rio de Janeiro, 2014. Disponível em: <www.ibge.gov.br>. Acesso em: 27 abr. 2018.

MEDEIROS, Fabíola de Araújo Leite; RODRIGUES, Ranielly Pereira; NÓBREGA, Maria Miriam Lima da. Visão de acadêmicos de enfermagem em relação ao processo de envelhecimento. Revista da Rede de Enfermagem do Nordeste, Fortaleza, v. 13, n. 4, p. 825-833, 2012. Disponível em: <http://www.periodicos.ufc.br/rene/article/ view/4041/3170>. Acesso em: 20 abr. 2015 
MIRANDA, Gabriella Morais Duarte; MENDES, Antonio da Cruz Gouveia; SILVA Ana Lucia Andrade da. O envelhecimento populacional brasileiro: desafios e consequências sociais atuais e futuras. Revista Brasileira de Geriatria e Gerontologia, Rio de Janeiro, v. 19, n. 3, p. 507-519, 2016. Disponível em: <http://www.scielo.br/ pdf/rbgg/v19n3/pt_1809-9823-rbgg-19-03-00507.pdf>. Acesso em: 7 fev. 2016.

MORAIS, Fernando Antônio de Andrade. Respeito aos idosos como valor humano. Revista Científica Semana Acadêmica, Fortaleza, v. 1, maio 2015. Disponível em: $<$ https://semanaacademica.org.br/system/files/artigos/artigo-idosos.pdf>. Acesso em: 17 fev. 2017.

MOTTA, Alda Britto da. A atualidade do conceito de gerações na pesquisa sobre o envelhecimento. Sociedade \& Estado, Brasília, v. 25, n. 2, maio/ago. 2010. Disponível em: <http://dx.doi.org/10.1590/S0102-69922010000200005>. Acesso em: 18 jun. 2018.

ORGANIZAÇÃO MUNDIAL DA SAÚDE (OMS). Relatório mundial de envelhecimento e saúde. Genebra, 2015. Disponível em: <http://sbgg.org.br/wp-content/uploads/2015/10/ OMS-ENVELHECIMENTO-2015-port.pdf>. Acesso em: 7 dez. 2016.

PEREIRA, Jacqueline Mary Monteiro. A escola do riso e do esquecimento: idosos na educação de jovens e adultos. Educação em Foco, Juiz de Fora, v. 16, n. 2, p. 11-38, fev. 2012. Disponível em: <http://www.uff.br/revistaedufoco/files/2012/08/Texto-014. pdf>. Acesso em: 7 fev. 2016.

RAMOS, Paulo Roberto Barbosa. Rede de proteção e garantia dos direitos das pessoas idosas no Maranhão. Revista do Tribunal de Justiça do Estado do Maranhão, São Luís, v. 5, n. 2, jul./dez. 2011. Disponível em: <http://www.ampid.org.br/v1/wp-content/uploads/2012/12/REDE-DE-PROTECAO-E-GARANTIA-DOS-DIREITOS-DASPESSOAS-IDOSAS-NO-MARANHAO.pdf>. Acesso em: 7 fev. 2016.

ROLIM, Taiane da Cruz et al. Reflexões gerais sobre envelhecimento e sobre direitos garantidos pelo direito brasileiro contemporâneo. Boletim Jurídico, Uberaba, MG, ano 13, n. 1217, 2014. Disponível em: <https://www.boletimjuridico.com.br/doutrina/ artigo/3899/reflexoes-gerais-envelhecimento-direitos-garantidos-pelo-direito-brasileiro-contemporaneos. Acesso em: 21 fev. 2017.

ROSA, Marília Ceccon Salarini da; JORDÃO, Silvia Nogueira; DAMAZIO, Vera Maria. Envelhecimento ativo: novas perspectivas e oportunidades para o campo do design emocional. In: CONGRESSO BRASILEIRO DE PESQUISA E DESENVOLVIMENTO EM DESIGN, 11., 2014, Gramado. Design e fatores humanos. Design e emoção. São Paulo: Blucher Design Proceedings, 2014. Disponível em: <http://pdf.blucher.com. br.s3-sa-east-1.amazonaws.com/designproceedings/11ped/00804.pdf>. Acesso em: 18 jun. 2018.

SANT'ANA-LOOS, René Simonato. A condução do bom viver na velhice: um ensaio sobre ética, felicidade e morte. Psicologia Argumento, Curitiba, v. 34, n. 85, p. 89-103, jan./ mar. 2016. Disponivel em: <http://periodicos.pucpr.br/index.php/psicologiaargumento/ article/view23310>. Acesso em: 10 fev. 2018.

SCORTEGAGNA, Paola Andressa; OLIVEIRA, Rita Cássia. Idoso: um novo ator social. In: SEMINÁRIO DE PESQUISA EM EDUCAÇÃO DA REGIÃO SUL, 9., 2012, Caxias do Sul, RS. Movimentos sociais, sujeitos e processos educativos. Caxias do Sul: Universidade de Caxias do Sul, 2012. Disponível em: <http://www.ucs.br/etc/conferencias/ index.php/anpedsul/9anpedsul/paper/viewFile/1886/73>. Acesso em: 7 fev. 2016.

SICCO, Juliana de Mattos. Abordagens pedagógicas sobre o envelhecimento: das possibilidades da inserção dos estudos gerontológicos no currículo escola. 2011. 62 f. Trabalho de Conclusão de Curso (Graduação em Pedagogia)-Universidade Federal do Rio Grande do Sul, Porto Alegre, 2011. Disponível em: <http://hdl.handle. net/10183/32079>. Acesso em: 7 abr. 2015. 
Data de Submissão: 31/05/2017

Data de Aprovação: 28/05/2018
UNIVERSIDADE CATÓLICA PORTUGUESA. Centro de Estudos dos Povos e Culturas de Expressão Portuguesa. O envelhecimento da população: dependência, ativação e qualidade. Relatório final. Coordenação Roberto Carneiro. Lisboa: Universidade Católica Portuguesa, 2012. Disponível em: <http://www.qren.pt/np4/np4/?newsld=1334\&file Name=envelhecimento_populacao.pdf>. Acesso em: 15 dez. 2016. 